\title{
Rationale and design of a prospective study: Cervical Dystonia Patient Registry for Observation of OnaBotulinumtoxinA Efficacy (CD PROBE)
}

Joseph Jankovic ${ }^{1 *}$, Charles H Adler ${ }^{2}$, P David Charles ${ }^{3}$, Cynthia Comella $^{4}$, Mark Stacy ${ }^{5}$, Marc Schwartz ${ }^{6}$, Susan M Sutch ${ }^{7}$, Mitchell F Brin ${ }^{8,9}$ and Spyridon Papapetropoulos ${ }^{10,11}$

\begin{abstract}
Background: A registry of patients with cervical dystonia (Cervical Dystonia Patient Registry for Observation of onaBotulinumtoxinA Efficacy [CD PROBE]) was initiated to capture data regarding physician practices and patient outcomes with onabōtulinumtoxinA (BOTOX ${ }^{\circledR}$, Allergan, Inc., Irvine, CA, USA). Methods and baseline demographics from an interim analysis are provided.

Methods/Design: This is a prospective, multicenter, clinical registry in the United States enrolling subjects with cervical dystonia (CD) who are toxin naive and/or new to the physicians' practices, or who had been in a clinical trial but received their last injection $\geq 16$ weeks prior to enrollment. Subjects are followed over 3 injection cycles of onabotulinumtoxinA, with assessments at time of injection and 4-6 weeks later. Information on physician's practice, patient demographics, CD disease history, duration of treatment intervals and neurotoxin dose, dilution, use of electromyography, and muscles injected are collected. Outcomes are assessed by physicians and subjects using various questionnaires.

Discussion: This ongoing registry includes 609 subjects with the following baseline data: $75.9 \%$ female, 93.6\% Caucasian, mean age $57.6 \pm 14.3$, age at symptom onset $48.3 \pm 16.2$, and time to diagnosis $5.4 \pm 8.6$ years, with an additional $1.0 \pm 3.5$ years before treatment. Of those employed at the time of diagnosis, $36.6 \%$ stopped working as a result of $C D$. CD PROBE, the largest clinical registry of $C D$ treatment, will provide useful data on current treatment practices with onabotulinumtoxinA, potentially leading to refinements for optimization of outcomes.
\end{abstract}

Trial registration: NCT00836017

\section{Background}

Cervical dystonia (CD), the most common form of adultonset focal dystonia, is manifested by sustained, involuntary contractions of the cervical musculature [1]. Patients usually present with pain and postural changes of the neck, often associated with irregular head tremor (dystonic tremor) [2]. Impaired neck mobility, chronic pain, and a reduction in the patient's self-image may adversely impact quality of life and result in disability $[3,4]$.

Physicians and patients had few treatment options prior to the introduction of botulinum toxin for CD over a quarter century ago [5]. Supported with evidence

\footnotetext{
* Correspondence: josephj@bcm.edu

'Baylor College of Medicine, Department of Neurology, Houston, TX, USA Full list of author information is available at the end of the article
}

from randomized controlled trials and meta-analyses, botulinum toxin has become the treatment of choice for CD [6,7]. An evidence-based review by the Therapeutics and Technology Assessment Subcommittee of the American Academy of Neurology concluded that botulinum toxin should be offered as a treatment option to patients with $C D$, a level A recommendation [8]. Botulinum toxin exerts its effect by inhibiting the presynaptic release of acetylcholine from peripheral terminals of motor neurons, thus causing chemodenervation and weakness of the injected muscle [9].

Four botulinum toxin products are approved for $\mathrm{CD}$. Three are serotype A (onabotulinumtoxinA [BOTOX ${ }^{\circledR}$, Allergan, Inc., Irvine, CA, USA]; abobotulinumtoxinA [Dysport $^{\mathbb{B}}$, Ipsen, Paris, France]; incobotulinumtoxinA

\section{Biomed Central}


[Xeomin ${ }^{\circledR}$, Merz Pharmaceuticals GmbH, Frankfurt, Germany]) and one is serotype B (rimabotulinumtoxinB $\left[\right.$ Myobloc $^{\circledR} /$ Neurobloc $^{\circledR}$, Solstice Neurosciences, San Francisco, CA, USA]). Each differs in molecular structure, formulation, and clinical profiles. There is no international potency reference standard for botulinum toxins and each formulation of botulinum toxin is different. Therefore, the units of activity are specific to each product and not interchangeable with those of any other botulinum toxins [10].

The objective of this paper is to describe the rationale, study design, and baseline characteristics of patients participating in Cervical Dystonia Patient Registry for Observation of onabotulinumtoxinA Efficacy (CD PROBE; NCT00836017), a large observational study designed to capture data on the clinical presentation, dosing of onabotulinumtoxinA, and treatment outcomes in patients with CD. Despite years of use in thousands of patients and clinical evidence from randomized controlled trials, questions remain regarding the optimal use of onabotulinumtoxin A for $\mathrm{CD}$. In disorders, such as $\mathrm{CD}$, where there is variability in clinical presentation and severity of symptoms, as well as a variety of comorbidities and use of concomitant medications, optimal treatment schemas may not be available from controlled clinical trials.

Experience indicates that proper muscle selection and dose are key determinants for a good response. However, in current practice, there is lack of consensus regarding technical aspects of the use of onabotulinumtoxinA, such as the optimal dose, dilution ratios, number of injection sites, combination and number of muscles to inject, dosing interval, and targeting procedure [10-15]. Determinants that impact treatment decisions, such as disease severity and clinical presentation, have not been clearly identified. Furthermore, specialists involved in the treatment of CD, including neurologists and physiatrists, may use different approaches to treatment and injection techniques, for which the effect on outcomes is unknown. A number of studies have shown that $C D$ adversely affects quality of life $[4,16,17]$ and symptom relief following botulinum toxin treatment results in improvement [18-22]. However, many quality of life measures used in prior clinical trials were not disease-specific and were not sensitive enough to detect clinically relevant changes.

By capturing real-world treatment practices and patient outcomes, CD PROBE will attempt to answer a number of clinical questions noted above or, at minimum, generate reasonable hypotheses for further investigation, to optimize outcomes among CD patients being treated with onabotulinumtoxinA.

\section{Methods/Design}

The primary objectives for CD PROBE, as predefined by the CD PROBE Charter Committee (JJ, MS, CA, PDC,
$\mathrm{CC}$, and $\mathrm{MB}$ ) are to determine if:

- the presentation of anatomical subtypes of CD correlate with the Toronto Western Spasmodic Torticollis Rating Scale (TWSTRS) scores and global assessment of severity rating;

- specific presentations of CD inform treatment choices (muscles injected, number of sites injected, dose, and dilution);

- there are clinically definable severity subtypes (e.g. mild, moderate, severe) that correlate with CD scales/questionnaires;

- a new pictorial version of a scale to assess disease severity, the Pictorial Spasmodic Torticollis Rating Scale (P-STRS), correlates with other measures and is sensitive to change with treatment;

- the impact of disease and treatment affects quality of life;

- there are potential predictors of outcomes, including baseline presentation, treatment approach, injector's practice characteristics, and adverse effects.

\section{The CD PROBE Study}

CD PROBE is a multicenter, national, prospective, standard-of-care, observational clinical registry designed to capture real-world clinical practices of neurologists, physiatrists, and other physicians who regularly treat CD. Including a range of clinical practices will allow comparison of treatment patterns for CD between physician groups having a wide range of experience in treating CD.

\section{Subjects}

This prospective clinical registry includes subjects with a diagnosis of CD, who in the clinical judgment of the investigator, are considered to be candidates for onabotulinumtoxinA therapy and/or who are new to the physician's practice or new to botulinum toxin therapy. Subjects who had previously participated in a clinical trial using botulinum toxin may be included if the time since their last dose is greater than 16 weeks. Subjects excluded are those planning elective surgery during the study; women who are nursing, pregnant, or planning a pregnancy; subjects with a history of poor compliance with medical treatment; and any condition or situation which, in the physician's opinion, could place the subject at risk, confound the registry data, or interfere significantly with the subject's participation in the registry. Institutional Review Board approval was granted at each participating site and written informed consent will be obtained from all patients prior to any study procedures being performed.

Baseline information collected includes demographics; history of CD diagnosis; and past treatments, comorbidities, and medications, including over-the-counter 
medications. Although CD presents with mixed symptoms, the $\mathrm{CD}$ classification of the predominant feature (anterocollis, lateralcollis, retrocollis, or torticollis) and the predominant direction of pull is recorded. Information is also collected that characterizes the physicians' practice and their experience with botulinum toxin (Table 1).

The aim of this study is to gain valuable information on the current treatment of $\mathrm{CD}$ with various patient types and different clinical practices, which will require a large number of subjects to be enrolled. With 600 patients enrolled as of February 2011, it is anticipated that more than 1,000 patients will be enrolled by the end of 2011.

\section{Visits and assessments}

The study period includes 3 injection cycles of onabotulinumtoxinA. Subjects are evaluated for safety and efficacy at each injection and at the peak effect 4 to 6 weeks following the injection. Follow-up visits after the first and second injections are via a telephone interview and follow-up after the third injection at the physician's office (Figure 1). Baseline data are collected prior to the first injection. The dosing and injection pattern are those customary for the practice of the physician. Information is collected on the dilution of onabotulinumtoxin A, dosing, use of electromyography, and muscles injected.

A comprehensive evaluation of outcomes is made by physicians and subjects using questionnaires that assess disease-specific outcomes, severity and improvement of symptoms, impact on overall well-being, quality of life, and impact of CD on work productivity and utilization of healthcare resources (Figure 1). The assessments that are made by the physician include the following:

1. TWSTRS is a validated, disease-specific questionnaire that comprises 3 subscales assessing severity
( 0 to 35 ), disability (0 to 30 ), and pain ( 0 to 20 ), including a total score (0 to 85) [23]. It is the most commonly used outcome measure in clinical trials of $\mathrm{CD}$ and botulinum toxins [9].

2. P-STRS is a new, disease-specific tool being developed to assess CD severity. Based on the TWSTRS severity subscale, P-STRS uses pictorial representations of the anatomical head and neck position. Preliminary assessments indicate that it is a valid and reliable tool that is sensitive to symptom improvement following treatment [24].

3. Clinician Global Impression of Change (CGIC) is a general questionnaire that provides the physician's assessment of the global impression of change using a 7-point scale ranging from "very much improved" to "very much worse" [25]. This questionnaire is used to determine if the change is clinically meaningful.

4. CD severity rating is the physician's assessment of the severity (mild, moderate, or severe) of the symptoms directly related to $\mathrm{CD}$. This assessment establishes clinically relevant "cut points" with questionnaires that may help physicians in optimizing treatment with onabotulinumtoxin A based on the severity of symptoms.

Patient-reported outcomes are assessed using a variety of questionnaires that evaluate symptoms and the impact of CD-associated symptoms on their daily living and are as follows:

1. Pain Numeric Rating Scale (PNRS) is a single-item questionnaire of the current level of pain on a scale from 0 to 10 [26].

2. Post-injection pain questionnaire is a 2-item questionnaire that assesses if neck pain was relieved during the month after onabotulinumtoxinA injection. If some pain relief occurred, subjects are asked to

Table 1 Information collected to characterize the treating physician's practice site and experience in using botulinum toxin for CD

\begin{tabular}{ll}
\hline Physician specialty & $\circ$ Neurologist \\
& $\circ$ Physical medicine and rehabilitation \\
& $\circ$ General practitioner \\
& $\circ$ Pain specialist \\
\hline Type of practice & $\circ$ Private, academic, health maintenance organization, general neurology, movement disorders \\
& focused \\
& $\circ$ Total number of patients seen per week \\
& $\circ$ Number of CD patients per week \\
& $\circ$ Total number of CD patients in practice \\
\hline Experience in practice and with botulinum toxin & $\circ$ Years of treating CD with botulinum toxin \\
for CD & $\circ$ Clinical research experience with botulinum toxin \\
& $\circ$ Formal botulinum toxin injection training \\
& $\circ$ Years in practice \\
& $\circ$ Board certification \\
\hline
\end{tabular}

CD: cervical dystonia. 


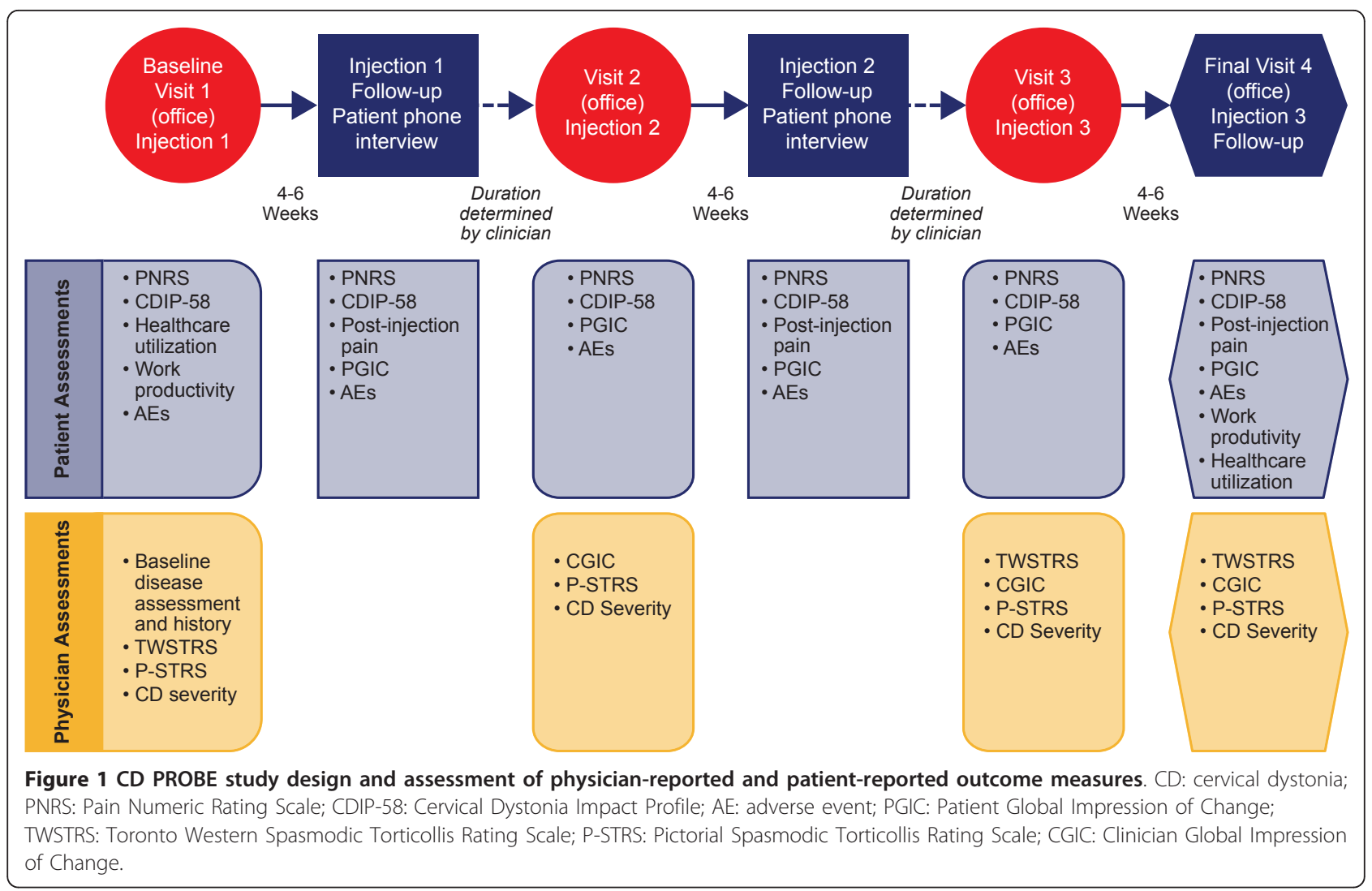

provide the number of days after injection before they experienced relief of neck pain.

3. Patient Global Impression of Change (PGIC) is a general questionnaire that assesses the change in health status since the start of the study using a 7point scale ranging from "very much improved" to "very much worse." It provides insight into the clinical value of the treatment [27].

4. Cervical Dystonia Impact Profile (CDIP-58) is a validated, disease-specific questionnaire that measures quality of life using 58 items that form 8 distinct subscales (head and neck, pain and discomfort, upper limb activities, walking, sleep, annoyance, mood, and psychological). It is more sensitive in detecting statistical and clinical change than comparable subscales of the SF-36, Functional Disability Scale, and Pain and Activities of Daily Living subscales of the TWSTRS [20,28].

5. Healthcare utilization questionnaire was developed for this study and is used to assess the use of healthcare resources (doctor and allied healthcare visits, emergency department visits, and hospitalizations) for treatment of CD symptoms.

6. Work productivity questionnaire prospectively elicits information regarding employment status, effect of $\mathrm{CD}$ on employment and productivity, and impact of treatment in restoring employment status [29].

Subjects who do not achieve any relief in symptoms 1 month after the first injection are assessed for a cause of the lack of response, according to routine medical practice, and then appropriateness of therapy, site of injection, dosage, and other factors are re-evaluated. The unilateral brow injection testing or serum antibody testing can be used to assess if toxin neutralizing antibodies are the cause of the lack of response [30]. Subjects are withdrawn from the study if they fail the brow test or if neutralizing antibodies are present.

Safety and tolerability are documented at each visit, with notation of the occurrence of adverse events, date of onset and resolution (if applicable), severity (mild, moderate, or severe), duration, frequency, relationship to study treatment, remedial actions, and outcome.

\section{Statistical analysis plan}

The CD PROBE study design is a clinical registry; therefore, there is no prespecified hypothesis. Descriptive statistics and exploratory analyses of baseline and posttreatment outcome data will be performed. All analyses will be performed using $\mathrm{R}$ version 2.12.1 or greater (The 
Table 2 Subject baseline demographics and disease characteristics

\begin{tabular}{|c|c|}
\hline $\begin{array}{l}\text { Characteristic } \\
(\mathrm{n}=609)^{*}\end{array}$ & $\begin{array}{c}\mathrm{n}(\%) \underset{\text { or mean }}{\text { (range) }} \pm \mathrm{SD} \\
\end{array}$ \\
\hline Gender, female & $462(75.9)$ \\
\hline Age, y & $57.6 \pm 14.3(19.4-90.2)$ \\
\hline \multicolumn{2}{|l|}{ Race/Ethnicity } \\
\hline White & $570(93.6)$ \\
\hline Hispanic & $17(2.8)$ \\
\hline Asian & $11(1.8)$ \\
\hline Black & $9(1.5)$ \\
\hline Native American & $1(0.2)$ \\
\hline Other & $1(0.2)$ \\
\hline $\mathrm{BMl}, \mathrm{kg} / \mathrm{m}^{2}$ & $26.4 \pm 5.4$ \\
\hline Age at CD symptom onset, y $(n=608)$ & $48.3 \pm 16.2(0.0-89.3)$ \\
\hline $\begin{array}{l}\text { Time from CD onset to CD diagnosis, y ( } n \\
=608 \text { ) }\end{array}$ & $5.4 \pm 8.6(-0.3-53.7)$ \\
\hline $\begin{array}{l}\text { Time to } C D \text { treatment after diagnosis, y }(\mathrm{n} \\
=608)\end{array}$ & $1.0 \pm 3.5(-0.3-31.4)$ \\
\hline Total TWSTRS $(n=604)$ & $38.2 \pm 13.2(4-077.0)$ \\
\hline
\end{tabular}

*Number of patients with data was 609 unless otherwise specified. SD: standard deviation; BMI: body mass index; CD: cervical dystonia; TWSTRS: Toronto Western Spasmodic Torticollis Rating Scale.

R Foundation for Statistical Computing; http://www.rproject.org/).

\section{Baseline results}

As of February 4, 2011, 613 subjects have been enrolled into CD PROBE from 76 centers across the United States. Of the 77 principal investigators who have enrolled patients into CD PROBE, 68 are neurologists, 8 are physical medicine and rehabilitation specialists, and 1 is a pain specialist. Baseline demographics and disease characteristics have been tabulated for 609 subjects and are shown in Table 2. Most subjects (63.7\%) were botulinum toxin-naïve and only $2.5 \%$ had previously received other forms of treatment (8 surgical denervation, 5 deep brain stimulation, 1 phenol injection, and 1 muscle resection surgery). Baseline information regarding the impact of having $\mathrm{CD}$ on work productivity is shown in Table 3.

\section{Discussion}

Onabotulinumtoxin A is a safe and effective treatment for $C D$ that improves the quality of life of sufferers [20-22]. Multiple outcome measures, including those assessed by patients and physicians, have been used to demonstrate effectiveness. In CD PROBE, comprehensive questionnaires, clinical rating scales, and other assessments are used to optimize the information collected. This large clinical registry of prospectively followed patients will allow analyses of determinants of outcome and adverse effects. Although onabotulinumtoxinA has been shown to be generally well tolerated with an acceptable adverse event profile, the occurrence of troublesome side effects, such as muscular weakness and dysphagia, and more systemic side effects, such as occasional malaise and other flu-like symptoms [31], may potentially lead to considerable disability and discontinuation of further treatment. Risk factors for the occurrence of adverse effects will be evaluated.

The baseline demographics and clinical characteristics of the CD PROBE population suggest that this cohort is representative of the general population with $C D$ $[32,33]$. As previously reported [34-38], symptoms of $\mathrm{CD}$ typically emerge in the fifth decade of life and the disorder is more frequent in women than in men. In our population of $613 \mathrm{CD}$ subjects, $63.7 \%$ of whom were never treated with botulinum toxin, the mean age at symptom onset was $48.3 \pm 16.2$ years, and the average duration of symptoms was $5.4 \pm 8.6$ years. The disabling nature of $\mathrm{CD}$ is supported by the findings that $36.6 \%$

Table 3 Work productivity assessment of patients at baseline

\begin{tabular}{lcl}
\hline Work productivity assessment & No. of patients & Response, $\mathbf{n}$ (\%) or mean \pm SD \\
\hline Employed at baseline & 575 & Yes: 262 (45.6) \\
\hline Employed when CD symptoms began & 313 & Yes: 161 (51.4) \\
\hline Stopped working due to CD & 161 & Yes: 59 (36.6) \\
\hline Employment status affected by CD & 262 & • Different job with less responsibility or pay: 14 (5.3) \\
& & • Same job, reduced hours or responsibility: 50 (19.1) \\
\hline Missed work in past month due to CD & & Yes: $74(28.4)$ \\
\hline Number of missed work days in past month & 261 & $5.7 \pm 11.6$ \\
\hline Decreased productivity due to CD & 74 & Yes: $150(57.5)$ \\
\hline Estimated decrease in work productivity (\%) & 261 & $72.1 \pm 20.5$ \\
\hline Have received disability benefits due to CD & 150 & Yes: $12(4.6)$ \\
\hline Duration of disability benefits (months) & 262 & $33.2 \pm 60.8$ \\
\hline
\end{tabular}

CD: cervical dystonia; SD: standard deviation. 
stopped working because of CD, $28.4 \%$ missed work because of $\mathrm{CD}$ in the past month (the average number of days missed was 5.7 days), and $57.5 \%$ felt that their productivity was decreased due to $\mathrm{CD}$ (Table 3 ).

Large clinical registries, such as CD PROBE, can inform clinical practice by providing substantial amounts of data; however, they also have inherent limitations. The lack of a controlled design and a prespecified statistical analysis plan leaves the ability to answer clinical questions with statistical power to chance; therefore, large numbers of subjects are needed. By not controlling the inclusion/exclusion of patients in clinical registries, it is more likely that subjects with comorbid conditions will be included compared with those typically enrolled in controlled trials. Nonetheless, clinical registries may provide data on the clinical nuances of treatment that are not generally obtainable from randomized controlled trials and, therefore, are more representative of the "real-world" experience.

CD PROBE is anticipated to provide clinically relevant information about disease-specific outcomes following treatment with onabotulinumtoxinA, including reduction in pain, change in disease severity, CD-related quality of life, impact of treatment on overall health, and economic aspects of $\mathrm{CD}$, including healthcare utilization and work productivity. The data generated from the study is anticipated to answer a number of questions regarding the optimal use of onabotulinumtoxinA for $\mathrm{CD}$ or generate hypotheses for investigation, with the ultimate goal to provide refinements in treatment to further improve outcomes in $\mathrm{CD}$ treatment.

\footnotetext{
Acknowledgements/Funding

CD PROBE is supported by Allergan, Inc. The authors thank Lee Ming Boo and Lisa Misell for their contributions to this study, and the CD PROBE Study Group for their dedication and care of the patients enrolled into the study. CD PROBE Study Group

Lefkos Aftonomos, CA; Pinky Agarwal, WA; Richard Barbano, NY; Peter Barbour, PA; Jay Bhatt, IN; David Bowers, TN; James Boyd, VT; Allison Brashear, NC; Mary Caire, TX; Mahan Chehrenama, VA; Paul Cullis, Ml; Khashayar Dashtipour, CA; Lisa Davidson, MN; Thomas Davis, TN; J Antonelle De Marcaida, CT; Christina Drafta, NY; Richard Dubinsky, KS; Jeffrey Esper, PA; Virgilio Evidente, AZ; Grace Forde, NY; Ramon Gil, FL; John Goudreau, Ml; David Greeley, WA; Gregory Hanes, FL; Robert Hauser, FL; Vanessa Hinson, SC; Patrick Hogan, WA; Tomas Holmlund, NY; Stuart Isaacson, FL; Bahman Jabbari, CT; Paul Jett, TN; John Kelemen, NY; Katie Kompoliti, IL; Rajeev Kumar, CO; Eugene Lai, TX; Julie Leegwater-Kim, MA; Peter LeWitt, Ml; TsaoWei Liang, PA; Steven Lo, DC; Zoltan Mari, MD; Anthony May, PA; Stephen McGuire, TX; Tamara Miller, CO; Eric Molho, NY; Srinivas Nalamachu, KS; Suneetha Nuthalapaty, TN; William Ondo, TX; Padraig O'Sullieabhain, TX; Fernando Pagan, DC; Atul Patel, KS; Gauri Pawar, WV; Diana Pollock, FL; Ben Renfroe, FL; Perry Richardson, DC; Michael Rivner, GA; Jason Rosenberg, SC; David Ross, FL; Michael Rossen, MA; Kyle Ruffing, FL; Aliya Sarwar, TX; Kapil Sethi, GA; Scott Sherman, AZ; Holly Shill, AZ; Carlos Singer, FL; Natividad Stover, AL; Thyagarajan Subramanian, PA; William Sunter, FL; David Swope, CA; Martin Taylor, OH; Margaret Tilton, NH; Richard Trosch, Ml; Winona Tse, NY; Miodrag Velickovic, NY; Maureen Watts, TX; Cindy Zadikoff, IL; Lin Zhang, CA; Chong-hao Zhao, CA.
}

\section{Author details}

${ }^{1}$ Baylor College of Medicine, Department of Neurology, Houston, TX, USA

${ }^{2}$ Mayo Clinic, Department of Neurology, Scottsdale, AZ, USA. ${ }^{3}$ Vanderbilt University Medical Center, Department of Neurology, Nashville, TN, USA ${ }^{4}$ Rush University Medical Center, Department of Neurological Sciences, Chicago, IL, USA. ${ }^{5}$ Duke University Medical Center, Department of Neurology, Durham, NC, USA. ${ }^{6}$ MedNet Solutions, Inc., Biostatistics, Minnetonka, MN, USA. ${ }^{7}$ UBC-Envision Group, Scientific Solutions, Philadelphia, PA, USA. ${ }^{8}$ Allergan, Inc., Global Drug Development, Irvine, CA, USA. ${ }^{9}$ University of California, School of Medicine, Irvine, CA, USA. ${ }^{10}$ Allergan, Inc., Medical Affairs, Irvine, CA, USA. ${ }^{11}$ University of Miami, Miller School of Medicine, Miami, FL, USA.

\section{Authors' contributions}

JJ was involved in the conception and design of the study, acquisition of data, analysis and interpretation of data, drafting all or part of the manuscript, critical revision of the manuscript for intellectual content, and overall supervision as first author. CHA was involved in the conception and design of the study, analysis and interpretation of data, and critical revision of the manuscript for intellectual content. PDC was involved with analysis and interpretation of data, critical revision of the manuscript for intellectual content, and supervision. M Stacy was involved in the conception and design of the study, critical revision of the manuscript for intellectual content, and supervision. M Schwartz, the statistician, was involved with conception and design of the study, acquisition of data, analysis and interpretation of data, drafting all or part of the manuscript, and statistical expertise. SMS was involved with acquisition of data, drafting all or part of the manuscript, administration, and provided technical support. MFB was involved in the conception and design of the study, analysis and interpretation of data, critical revision of the manuscript for intellectual content, obtaining funding, and supervision. SP was involved with conception and design of the study, acquisition of data, analysis and interpretation of data, drafting all or part of the manuscript, critical revision of the manuscript for intellectual content, obtaining funding, administrative and technical support, and supervision. All authors have read and approved the final manuscript.

\section{Competing interests}

J): Baylor College of Medicine receives income from grants and contracts with Allergan, Inc., Ipsen, and Merz Pharmaceuticals for research led by Dr Jankovic. Dr Jankovic is a paid consultant to or a board member of Allergan, Inc., EMD Serono, Inc., Lundbeck Inc., Merz Pharmaceuticals, Michael J Fox Foundation for Parkinson's Research, Teva Pharmaceutical Industries Ltd, and receives payments/royalties from Elsevier, MedLink, Neurology, Neurology in Clinical Practice, Neurotoxin Institute, Scientiae, and UpToDate, Inc. CHA: Received consulting fees from Allergan, Inc., Eli Lilly and Company, Ipsen, Medtronic, and Merck Serono.

PDC: Vanderbilt University receives income from grants and contracts with Allergan, Inc. and Medtronic for research led by Dr Charles. Dr Charles receives income from Allergan, Inc., Medtronic, and Pfizer Inc for education and consulting services.

M Stacy: Received compensation from Allergan, Inc., Boehringer Ingelheim, General Electric, Novartis, Osmotica Pharmaceutical Corp., Synosia Therapeutics, Schering-Plough, GlaxoSmithKline, Teva Pharmaceutical Industries Ltd, Biogen Idec, and Neurologix, Inc. for consulting, speaker bureau, protocol steering committee, and/or safety monitoring boards. $\mathrm{Dr}$ Stacy received royalties from Informa Press and research support from Ceregene, Inc., IMPAX, Michael J Fox Foundation for Parkinson's Reasearch, Neuraltus Pharmaceuticals, Inc., Novartis, Parkinson Study Group, and Schering-Plough.

M Schwartz: Employee of MedNet Solutions, Inc. who is contracted with Allergan, Inc. for data collection and statistical analysis.

SMS: Employed by UBC-Envision Group who contracted with Allergan, Inc. to provide professional writing assistance and project management support in the development of this manuscript.

MFB: Employed by Allergan, Inc. and holds Allergan stock.

SP: Employed by Allergan, Inc. and holds Allergan stock.

Received: 13 September 2011 Accepted: 4 November 2011 Published: 4 November 2011 
References

1. Jankovic J, Tsui J, Bergeron C: Prevalence of cervical dystonia and spasmodic torticollis in the United States general population. Parkinsonism Relat Disord 2007, 13:411-416.

2. Stacy M: Epidemiology, clinical presentation, and diagnosis of cervical dystonia. Neurol Clin 2008, 26(Suppl 1):23-42.

3. Rondot P, Marchand MP, Dellatolas G: Spasmodic torticollis-review of 220 patients. Can J Neurol Sci 1991, 18:143-151.

4. Camfield L, Ben-Shlomo Y, Warner T: Impact of cervical dystonia on quality of life. Mov Disord 2002, 17:838-841.

5. Jankovic J: Treatment of dystonia. Lancet Neurol 2006, 5:864-872.

6. Jankovic J: Botulinum toxin in clinical practice. J Neurol Neurosurg Psychiatry 2004, 75:951-957.

7. Tarsy D, Simon DK: Dystonia. N Engl J Med 2006, 355:818-829.

8. Simpson DM, Blitzer A, Brashear A, Comella C, Dubinsky R, Hallett M, Jankovic J, Karp B, Ludlow CL, Miyasaki JM, Naumann M, So Y: Assessment: Botulinum neurotoxin for the treatment of movement disorders (an evidence-based review): report of the Therapeutics and Technology Assessment Subcommittee of the American Academy of Neurology. Neurology 2008, 70:1699-1706.

9. Jankovic J: Botulinum toxin. In Encyclopedia of Movement Disorders. Volume 1. Edited by: Kompoliti K, Verhagen Metman L. Oxford: Academic Press; 2010:144-150.

10. Albanese A: Terminology for preparations of botulinum neurotoxins: what a difference a name makes. JAMA 2011, 305:89-90.

11. Sheean G: Cervical dystonia: unresolved issues and future challenges. Neurol Clin 2008, 26(Suppl 1):66-76.

12. Brans JW, Aramideh M, Koelman JH, Lindeboom R, Speelman JD, Ongerboer de Visser BW: Electromyography in cervical dystonia: changes after botulinum and trihexyphenidyl. Neurology 1998, 51:815-819.

13. Comella CL, Buchman AS, Tanner CM, Brown-Toms NC, Goetz CG: Botulinum toxin injection for spasmodic torticollis: increased magnitude of benefit with electromyographic assistance. Neurology 1992, 42:878-882.

14. Barbano RL: Needle EMG guidance for injection of botulinum toxin Needle EMG guidance is useful. Muscle Nerve 2001, 24:1567-1568.

15. Jankovic J: Needle EMG guidance for injection of botulinum toxin. Needle EMG guidance is rarely required. Muscle Nerve 2001, 24:1568-1570.

16. Müller J, Kemmler G, Wissel J, Schneider A, Voller B, Grossmann J, Diez J, Homann N, Wenning GK, Schnider P, Poewe W: The impact of blepharospasm and cervical dystonia on health-related quality of life and depression. J Neurol 2002, 249:842-846.

17. Ben-Shlomo Y, Camfield L, Warner T: What are the determinants of quality of life in people with cervical dystonia? J Neurol Neurosurg Psychiatry 2002, 72:608-614

18. Skogseid IM, Malt UF, Røislien J, Kerty E: Determinants and status of quality of life after long-term botulinum toxin therapy for cervical dystonia. Eur J Neurol 2007, 14:1129-1137.

19. Slawek J, Friedman A, Potulska A, Krystkowiak P, Gervais C, Banach M, Ochudlo S, Budrewicz S, Reclawowicz D, Rynkowski M, Opala G: Factors affecting the health-related quality of life of patients with cervical dystonia and the impact of botulinum toxin type A injections. Funct Neurol 2007, 22:95-100

20. Cano SJ, Hobart JC, Edwards M, Fitzpatrick R, Bhatia K, Thompson AJ, Warner T: CDIP-58 can measure the impact of botulinum toxin treatment in cervical dystonia. Neurology 2006, 67:2230-2232.

21. Hilker R, Schischniaschvili M, Ghaemi M, Jacobs A, Rudolf J: Health related quality of life is improved by botulinum neurotoxin type $A$ in long term treated patients with focal dystonia. J Neurol Neurosurg Psychiatry 2001, 71:193-199.

22. Brans JW, Lindeboom R, Aramideh M, Speelman JD: Long-term effect of botulinum toxin on impairment and functional health in cervical dystonia. Neurology 1998, 50:1461-1463.

23. Consky E, Lang A: Clinical assessments of patients with cervical dystonia. In Therapy with Botulinum Toxin. Edited by: Jankovic J, Hallett M. New York: Marcel Dekker, Inc; 1994:211-237.

24. Papapetropoulos S, Rosa K, Comella C, Boo LM, Brin MF: Validity and reliability of the Pictorial Spasmodic Torticollis Rating Scale (P-STRS). Neurology 2011, 76:A587.

25. Guy W, Bonato RR, editors: Manual for the ECDEU Assessment Battery Chevy Chase: National Institute of Mental Health; 1976.
26. Dworkin RH, Turk DC, Farrar JT, Haythornthwaite JA, Jensen MP, Katz NP, et al: Core outcome measures for chronic pain clinical trials: IMMPACT recommendations. Pain 2005, 113:9-19.

27. Turk DC, Dworkin RH, Allen RR, Bellamy N, Brandenburg N, Carr DB, Cleeland C, Dionne R, Farrar JT, Galer BS, Hewitt DJ, Jadad AR, Katz NP, Kramer LD, Manning DC, McCormick CG, McDermott MP, McGrath P, Quessy S, Rappaport BA, Robinson JP, Royal MA, Simon L, Stauffer JW Stein W, Tollett J, Witter J: Core outcome domains for chronic pain clinical trials: IMMPACT recommendations. Pain 2003, 106:337-345.

28. Cano SJ, Warner TT, Linacre JM, Bhatia KP, Thompson AJ, Fitzpatrick R, Hobart JC: Capturing the true burden of dystonia on patients: the Cervical Dystonia Impact Profile (CDIP-58). Neurology 2004, 63:1629-1633.

29. Molho ES, Agarwal N, Regan K, Higgins DS, Factor SA: Effect of cervical dystonia on employment: a retrospective analysis of the ability of treatment to restore premorbid employment status. Mov Disord 2009, 24:1384-1387.

30. Hanna PA, Jankovic J, Vincent A: Comparison of mouse bioassay and immunoprecipitation assay for botulinum toxin antibodies. J Neurol Neurosurg Psychiatry 1999, 66:612-616.

31. Baizabal Carvallo J, Jankovic J, Pappert E: Flu-like symptoms following botulinum toxin therapy. Toxicon 2011.

32. Jankovic J, Leder S, Warner D, Schwartz K: Cervical dystonia: clinical findings and associated movement disorders. Neurology 1991, 41:1088-1091.

33. Chan J, Brin MF, Fahn S: Idiopathic cervical dystonia: clinical characteristics. Mov Disord 1991, 6:119-126.

34. Brashear A, Hogan P, Wooten-Watts M, Marchetti A, Magar R, Martin J: Longitudinal assessment of the dose consistency of botulinum toxin type A (BOTOX) for cervical dystonia. Adv Ther 2005, 22:49-55.

35. Truong D, Brodsky M, Lew M, Brashear A, Jankovic J, Molho E, Orlova O, Timerbaeva S: Long-term efficacy and safety of botulinum toxin type A (Dysport) in cervical dystonia. Parkinsonism Relat Disord 2010, 16:316-323.

36. Pappert EJ, Germanson T: Botulinum toxin type B vs. type A in toxinnaive patients with cervical dystonia: randomized, double-blind, noninferiority trial. Mov Disord 2008, 23:510-517.

37. Comella CL, Jankovic J, Shannon KM, Tsui J, Swenson M, Leurgans S, Fan W: Comparison of botulinum toxin serotypes $A$ and $B$ for the treatment of cervical dystonia. Neurology 2005, 65:1423-1429.

38. Factor SA, Molho ES, Evans S, Feustel PJ: Efficacy and safety of repeated doses of botulinum toxin type $B$ in type $A$ resistant and responsive cervical dystonia. Mov Disord 2005, 20:1152-1160.

\section{Pre-publication history}

The pre-publication history for this paper can be accessed here: http://www.biomedcentral.com/1471-2377/11/140/prepub

\section{doi:10.1186/1471-2377-11-140}

Cite this article as: Jankovic et al:: Rationale and design of a prospective study: Cervical Dystonia Patient Registry for Observation of OnaBotulinumtoxinA Efficacy (CD PROBE). BM $\overline{M C}$ Neurology 2011 11:140.

\section{Submit your next manuscript to BioMed Central and take full advantage of:}

- Convenient online submission

- Thorough peer review

- No space constraints or color figure charges

- Immediate publication on acceptance

- Inclusion in PubMed, CAS, Scopus and Google Scholar

- Research which is freely available for redistribution

Submit your manuscript at www.biomedcentral.com/submit
C Biomed Central 